\title{
Evaluation of Mixed-Phase Cloud Microphysics Parameterizations with the NCAR Single Column Climate Model (SCAM) and ARM Observations
}

Second Quarter 2007 ARM Metric Report

April 2007

Xiaohong Liu and Steven J. Ghan

Pacific Northwest National Laboratory

Richland, Washington

Shaocheng Xie

Lawrence Livermore National Laboratory

Livermore, California

Work supported by the U.S. Department of Energy,

Office of Science, Office of Biological and Environmental Research 


\section{Summary}

Mixed-phase stratus clouds are ubiquitous in the Arctic and play an important role in climate in this region. However, climate models have generally proven unsuccessful at simulating the partitioning of condensed water into liquid droplets and ice crystals in these Arctic clouds, which affect modeled cloud phase, cloud lifetime and radiative properties. An ice nucleation parameterization and a vapor deposition scheme were developed that together provide a physically-consistent treatment of mixed-phase clouds in global climate models. These schemes have been implemented in the National Center for Atmospheric Research (NCAR) Community Atmospheric Model Version 3 (CAM3). This report documents the performance of these schemes against ARM Mixed-phase Arctic Cloud Experiment (M-PACE) observations using the CAM single column model version (SCAM). SCAM with our new schemes has a more realistic simulation of the cloud phase structure and the partitioning of condensed water into liquid droplets against observations during the M-PACE than the standard CAM simulations. 


\section{Contents}

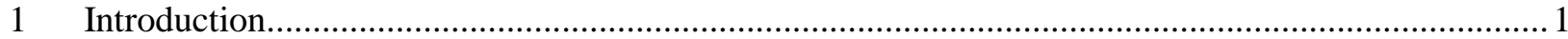

2 NCAR CAM Single Column Model (SCAM) .................................................................... 1

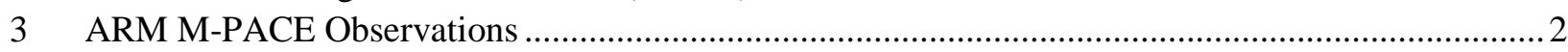

4 SCAM Results and Compariation against M-PACE Observations .................................................. 2

4.1 Simulations with Standard CAM Vertical Resolution........................................................ 2

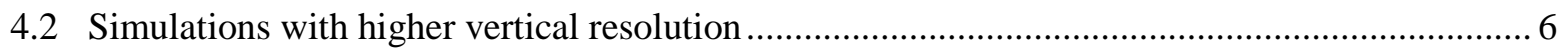

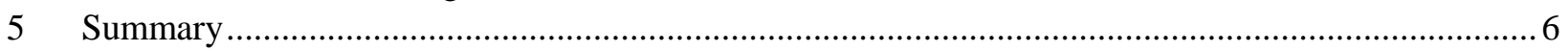

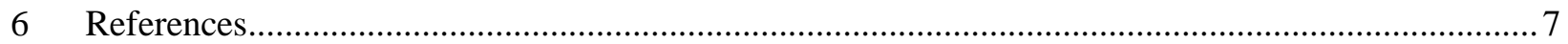

\section{Figures}

1 Liquid water content (LWC), and ice water content (IWC) as a function of altitudes and time calculated from the modified SCAM (left) and the standard SCAM (right) for the period from 17Z October 9 to $5 Z$ October 10.

2 (a) Liquid water content and temperature from a Citation spiral during the period of from $17 \mathrm{Z}$ October 9 to $5 \mathrm{Z}$ October 10 4

3 Liquid water fraction in total water in clouds as a function of temperature ......................................5

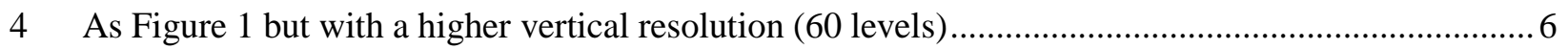




\title{
Evaluation of Mixed-Phase Cloud Microphysics Parameterizations with the NCAR Single Column Climate Model (SCAM) and ARM Observations
}

\author{
Second Quarter 2007 ARM Metric Report
}

\section{Introduction}

Clouds play an important role in the Arctic climate. Clouds determine the net long-wave radiation at the surface and also regulate incoming solar radiation in summer. Low-level boundary layer (BL) clouds tend to dominate in the Arctic with very high temporal frequencies in all seasons (Curry et al. 1996; Intrieri et al. 2002) and somewhat uniform spatial distributions (Vavrus 2004). Arctic boundary layer clouds are often characterized by the presence of persistent temperature inversions, humidity inversions, and strong, stably stratified layers (Pinto 1998). A particularly important feature is that these clouds are often mixed-phase even at quite low temperatures, consisting of liquid-water tops that precipitate ice (Pinto 1998).

To date, modeling of mixed-phase clouds and their phase state has proven challenging (Beesley and Moritz 1999; Harrington and Olsson 2001; Harrington et al. 1999; Morrison and Pinto 2005; Morrison et al. 2003; Vavrus 2004). The partitioning of condensed water into liquid droplets and ice crystals in most climate models is specified as a function of temperature, but in nature the partitioning varies with time, with cloud water forming initially but cloud ice eventually dominating as ice crystals nucleate and grow at the expense of cloud water. This two-stage (nucleation and growth) process of ice formation in clouds has been known to be important since the early work of Bergeron (1935) and Findeisen (1938). To provide a physically-consistent treatment of mixed-phase clouds in climate models, an ice nucleation parameterization (Liu and Penner 2005) and a water vapor deposition growth scheme (Rotstayn et al. 2000) have both been documented in the previous report and implemented in the NCAR Community Atmosphere Model (CAM Version 3). This report documents the performance of these schemes against ARM Mixed-phase Arctic Cloud Experiment (M-PACE) observations using the CAM single column model version (SCAM).

\section{NCAR CAM Single Column Model (SCAM)}

The NCAR single column CAM (SCAM) is a one-dimensional time dependent model in which the local time-rate-of-change of the large-scale state variables (e.g., temperature, moisture, momentum, cloud water, etc.) depends on specified horizontal flux divergences, a specified vertical motion field (from which the large-scale vertical advection terms are evaluated), and subgrid-scale sources, sinks and eddy transports. The subgrid-scale contributions are determined by the particular collection of physical parameterizations being investigated.

Two sets of simulations with the SCAM are performed: one with the standard CAM3 microphysics (standard SCAM) and another with the modified mixed-phase cloud microphysics (Liu and Penner 2005; Rostayn et al. 2000) (modified SCAM). Since the SCAM has a low vertical resolution to resolve the 
vertical structures of the mixed phase clouds (i.e., the single layer stratocumulus commonly occurring in the Arctic), sensitivity tests are conducted in which the vertical resolution is strongly increased from the standard 26 levels to 60 levels for both the Standard SCAM and Modified SCAM.

\section{ARM M-PACE Observations}

The Mixed-Phase Arctic Cloud Experiment (M-PACE) was conducted from late September through October 2004 in the vicinity of the Department of Energy North Slope of Alaska (NSA) field site. The overall objective of the project was to collect a focused set of observations needed to advance understanding of the dynamical and microphysical processes that lead to long-lived mixed-phase Arctic clouds. To this end, measurements of cloud and aerosol properties were made by aircraft and a suite of remote sensing devices (Verlinde et al. 2006). During the 17.5-day Intensive Observing Period (IOP) a sounding network of four stations was in place which launched 6-hourly radiosondes for most of the experiment. From these soundings and other data such as analyses from the European Centre for Medium Range Weather Forecasts (ECMWF), the LLNL ARM team has derived the large-scale advective forcings that is used to drive SCAM (Xie et al. 2006).

Low-level boundary layer clouds tend to dominate in the Arctic with very high temporal frequencies in all seasons (Curry et al. 1996; Intrieri et al. 2002). Single layer boundary layer mixed-phase clouds present in the period 9-10 October are selected for this study. This cloud system was formed as a result of east-northeast flow which brought cold near-surface air from the sea-ice located about $500 \mathrm{~km}$ to the north over the warm open ocean that was adjacent to the Alaska north coast. The microphysical properties of this cloud system were sampled by two Citation flights during this period. The data shows that the liquid water content increases with height above cloud base as would be expected for a stratocumulus cloud at the top of a well-mixed boundary layer. In general, liquid dominated near the tops of the clouds with precipitating ice (sometimes heavy) near the base - although it is noted that considerable variability exists between spirals.

\section{SCAM Results and Compariation against M-PACE Observations}

\subsection{Simulations with Standard CAM Vertical Resolution}

Figure 1 shows the modeled liquid water content (LWC) and ice water content (IWC) as a function of altitudes and time from the standard and modified SCAM for the period from 17Z October 9 to $5 Z$ October 10. The standard SCAM produces LWC and IWC profiles overlapping with each other in the mixed-phase clouds. The modified SCAM efficiently separates the LWC and IWC in clouds with liquid water dominating the water amount in the upper portion of mixed-phase clouds, while the clouds in the lower portion are purely ice phase with ice precipitating beneath. Figure 2 (a) shows the liquid water content and temperature from a University of North Dakota Citation aircraft spiral during the period; Figure 2 (b) shows a significant amount of ice was also present both in the cloud and beneath the liquid water cloud base. Thus SCAM with our physically-based treatment for mixed-phase clouds reproduces the observed cloud phase structures in the M-PACE. 


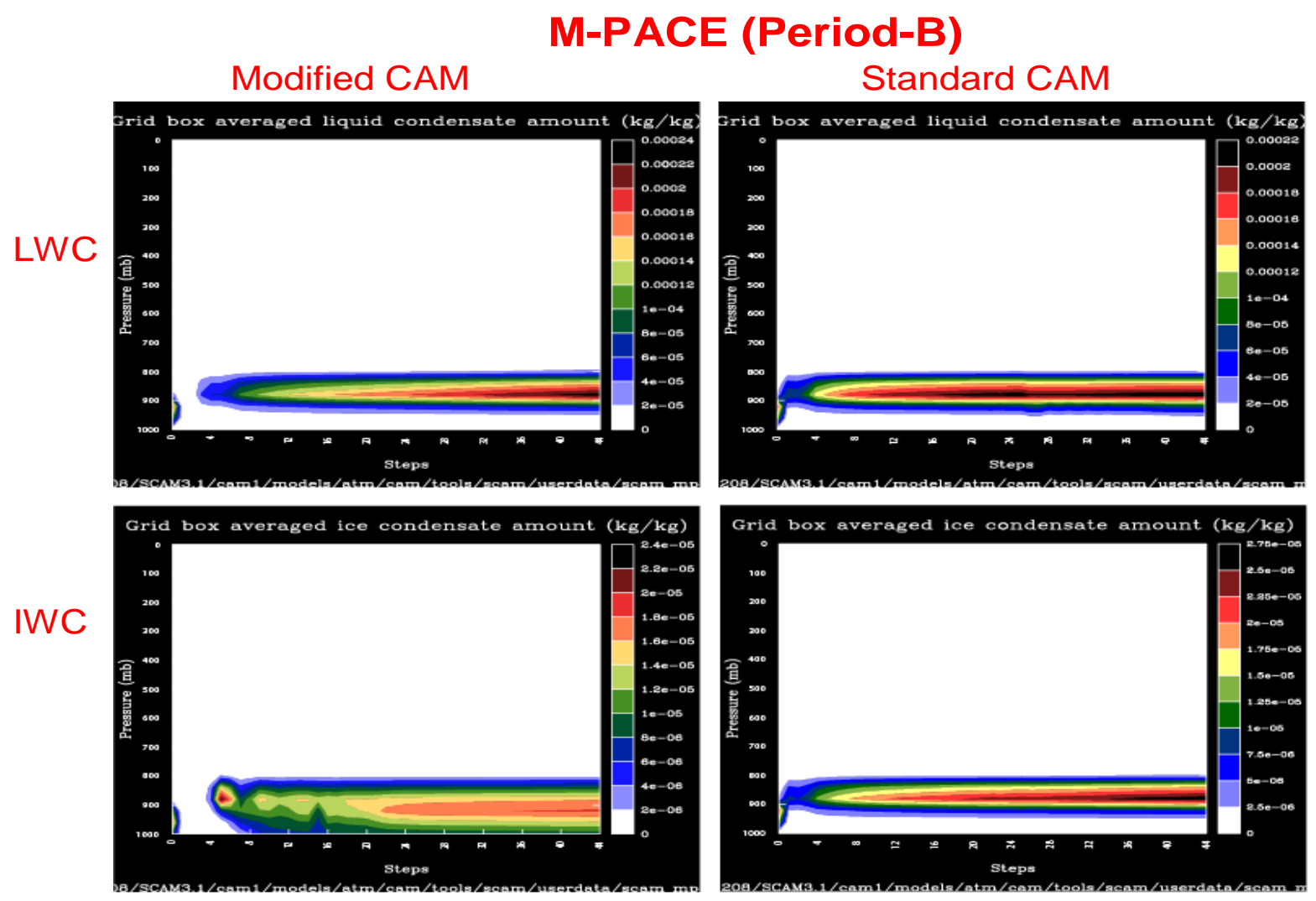

Figure 1. Liquid water content (LWC), and ice water content (IWC) as a function of altitudes and time calculated from the modified SCAM (left) and the standard SCAM (right) for the period from 17Z October 9 to $5 Z$ October 10. 
(a)

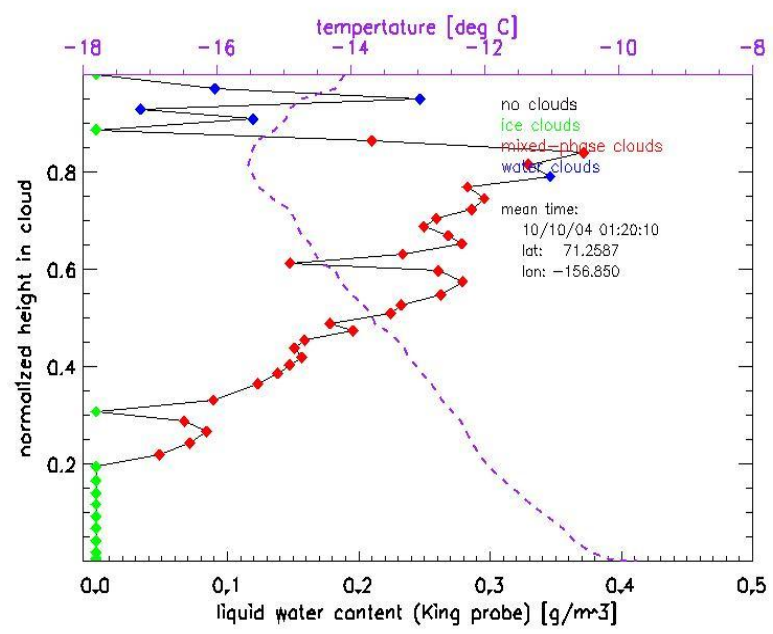

(b)

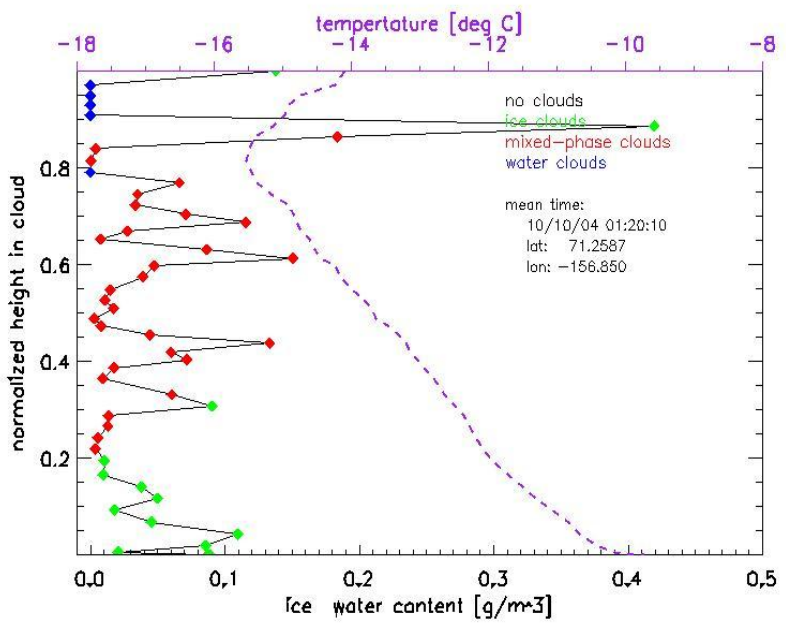

Figure 2 (a). Liquid water content and temperature from a Citation spiral during the period of from $17 Z$ October 9 to $5 Z$ October 10. The vertical axis is altitude normalized by the top and bottom of cloud. For example, a normalized height of 0.5 is in the middle of the cloud. Figure 2 (b) is the same as in Figure 2 (a), but for ice water content.

Figure 3 shows the liquid water fraction in the total water in clouds as a function of temperature as compiled from the model results and observations during the period of $17 Z$ October 9 to $5 Z$ October 10. Even through there are not many in-cloud points available due to the lower vertical resolution of SCAM, we can see that the modified SCAM produces the liquid water fraction agreeing with the observation better than the standard SCAM. 


\section{Boundary Layer Mixed-phase Clouds}

(17Z Oct. 9 - 5 Z Oct. 9, 2004)
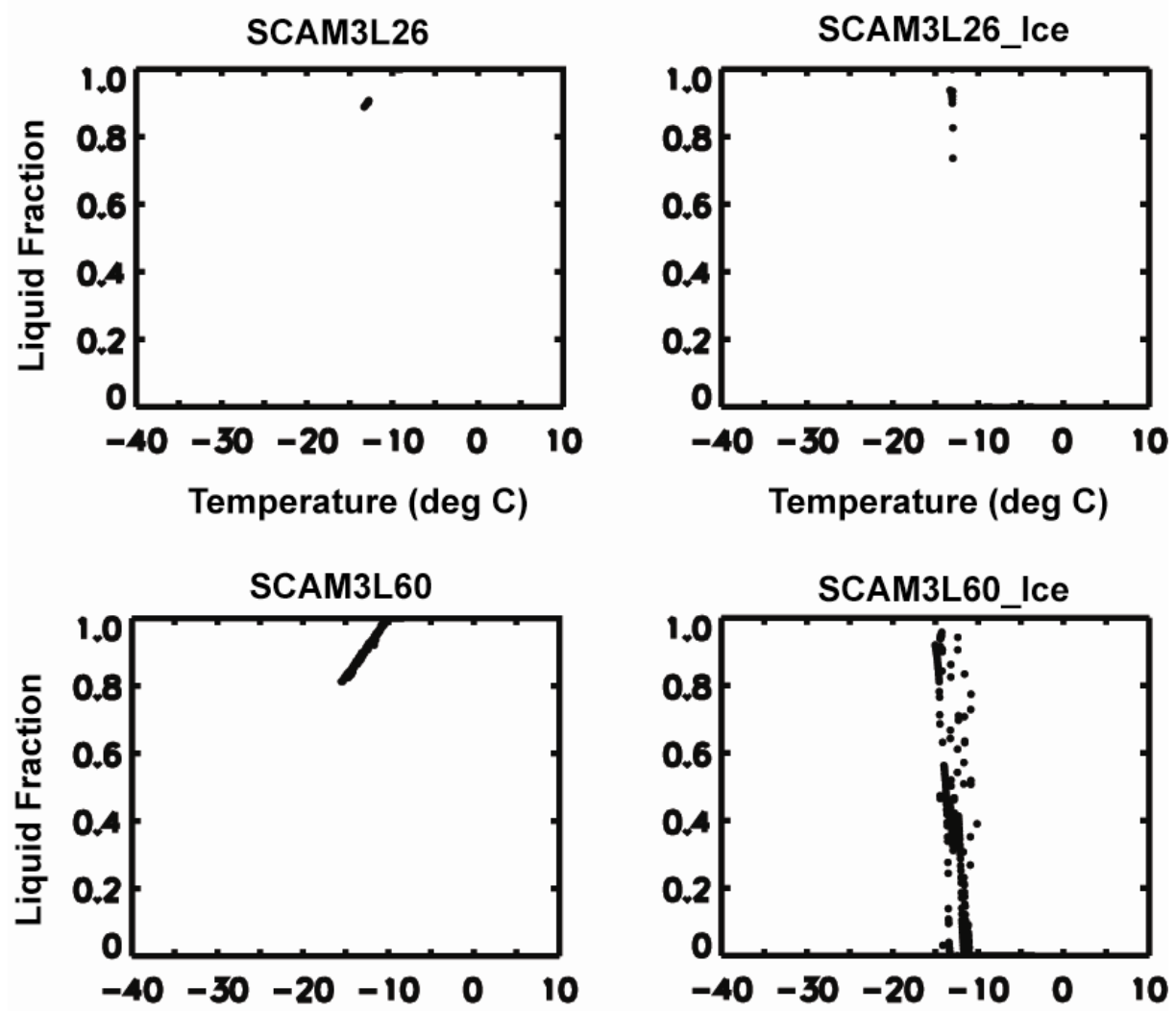

Temperature (deg C)

Temperature (deg C)

OBS

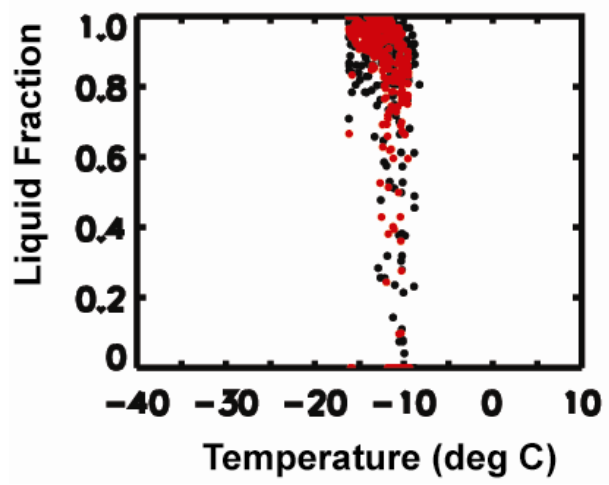

Figure 3. Liquid water fraction in total water in clouds as a function of temperature. Upper panel is for SCAM simulations (with standard microphysics (left) and modified microphysics (right)) with 26 vertical levels; middle panel is for SCAM simulations with 60 vertical levels; and the observations are shown in the lower panel (black and red dots representing two Citation flights). 


\subsection{Simulations with Higher Vertical Resolution}

Figure 4 is the same as Figure 1 but with a higher vertical resolution (60 levels). Obviously, the cloud phase structure as seen in Figure 1 appears with much better resolution. The statistics of liquid water fraction from these simulations is shown in Figure 3. The modified SCAM produces the liquid water fraction agreeing with observations much better than the standard SCAM. The liquid fraction from the standard SCAM simply follows the temperature dependence as prescribed in the standard SCAM (linear temperature interpolation between $-40^{\circ}$ and $-10^{\circ} \mathrm{C}$ ).

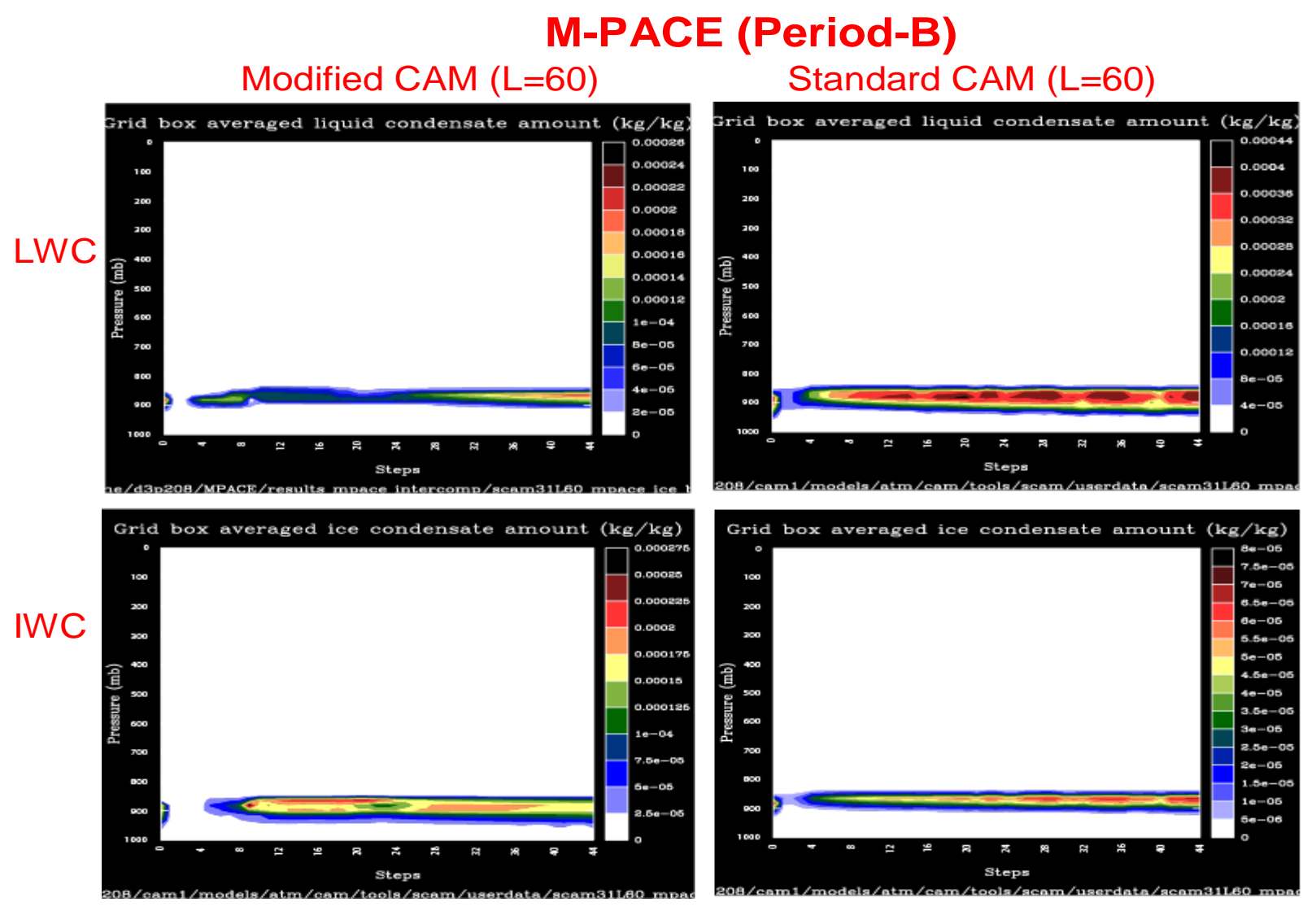

Figure 4. As Figure 1 but with a higher vertical resolution (60 levels).

\section{Summary}

In this report, a new mixed-phase cloud microphysics with Liu and Penner (2005) for ice nucleation and Rotstayn et al. (2000) for vapor deposition on ice crystals is tested under the NCAR single column climate model framework (SCAM). The model results with both the standard SCAM and modified SCAM are evaluated against ARM M-PACE observations for single-layer stratus clouds in the Arctic during the period of October 2004. SCAM with the modified microphysics has a more realistic prediction of the cloud phase structure and liquid water fraction against observations than the standard SCAM. These results can have important implications for the cloud radiative properties, surface radiation budget, precipitation and cloud lifetime as simulated in climate models. 


\section{References}

Beesley, JA and RE Moritz. 1999. "Toward an explanation of the annual cycle of cloudiness over the Arctic Ocean." Journal of Climate 12, 395-415.

Bergeron, T. 1935. "On the physics of cloud and precipitation." In Proceedings of the 5th Assembly U.G.G.I. Lisbon 2, 156.

Curry, JA, WB Rossow, D Randall, and JL Schramm. 1996. "Overview of Arctic cloud and radiation characteristics." Journal of Climate 9, 1731-1764.

Findeisen, W. 1938. "Die Kolloidmeteorologischen Vorgange bei der Niederschlasbildung (Collodial meteorological processes in the formation of precipitation)." Met. Z. 55, 121.

Harrington, JY and PQ Olsson. 2001. "On the potential influence of ice nuclei on surface-forced marine stratocumulus cloud dynamics." Journal of Geophysical Research 106, 27473-27484.

Harrington, JY, T Reisin, WR Cotton, and SM Kreidenweis. 1999. "Cloud resolving simulations of Arctic stratus - Part II: Transition-season clouds." Journal of Atmospheric Research 51, 45-75.

Intrieri, JM, MD Shupe, T Uttal, and BJ McCarty. 2002. "An annual cycle of Arctic cloud characteristics observed by radar and lidar at SHEBA." Journal of Geophysical Research 107, Article Number 8030.

Liu, X and JE Penner. 2005. "Ice nucleation parameterization for global models." Meteorologische Zeitschrift 14, No.4, 499-514.

Morrison, H and JO Pinto. 2005. "Mesoscale modeling of springtime Arctic mixed-phase stratiform clouds using a new two-moment bulk microphysics scheme." Journal of Atmospheric Science 62, 3683-3704.

Morrison, H, MD Shupe, and JA Curry. 2003. "Modeling clouds observed at SHEBA using a bulk microphysics parameterization implemented into a single-column model." Journal of Geophysical Research 108, doi:1029/2002JD002229.

Pinto, JO. 1998. "Autumnal mixed-phase cloudy boundary layers in the Arctic." Journal of Atmospheric Science 55, 2016-2038.

Rotstayn, LD, BF Ryan, and JJ Katzfey. 2000. "A scheme for calculation of the liquid fraction in mixedphase stratiform clouds in large-scale models." Monthly Weather Review 128, 1070-1088.

Xie, S, SA Klein, M Zhang, JJ Yio, RT Cederwall, and R McCoy. 2006. "Developing large-scale forcing data for single-column model and cloud-resolving model from the Mixed-Phase Arctic Cloud Experiment." Journal of Geophysical Research, submitted.

Vavrus, S. 2004. "The impact of cloud feedbacks on Arctic climate under greenhouse forcing." Journal of Climate 17, 603-615. 
Verlinde, J, JY Harrington, GM McFarquhar, VT Yannuzzi, A Avramov, S Greenberg, N Johnson, MR Poellot, JH Mather, DD Turner, BD Zak, TP Tooman, AJ Prenni, GL Kok, EW Eloranta, MD Ivey, CP Bahrmann, K Sassen, PJ DeMott, and AJ Heymsfield. 2006. "The mixed-phase Arctic cloud experiment (M-PACE)." Bulletin of the American Meteorological Society, submitted. 